\title{
Estudos de Tendências: contributo para uma abordagem de análise \\ e gestão da cultura
}

- Nelson Pinheiro Gomes ${ }^{1}$

- Suzana Amarante de Mendonça Cohen²

- Ana Marta Moreira Flores 3

P.49-81 


\title{
Estudos de Tendências: contributo para uma abordagem de análise e gestão da cultura
}

\begin{abstract}
RESUMO
O presente artigo pretende problematizar o desenvolvimento e o processo de consolidação dos Estudos de Tendências, enquanto área transversal com características transdisciplinares, que se desenvolveu em articulação com os conceitos e as práticas de áreas como os Estudos de Cultura. As várias perspectivas dos Estudos de Tendências e as suas diversas associações promovem um desenvolvimento disperso que se deve considerar e desconstruir, encontrando pontos em comum e práticas, ou perspectivas, distintas, com vista a uma maior coesão de conceitos e de metodologias. Neste sentido, importa apresentar um modelo de articulação para a identificação e a observação sistemáticas de tendências, no âmbito do estudo das mudanças ao nível da cultura e de mentalidades. Isto permite gerar um processo paralelo de análise cultural capaz de contribuir com as bases para a geração de soluções estratégicas para questões institucionais e sociais, numa nova abordagem ao nível da gestão da cultura.
\end{abstract}

Palavras-chave: tendências, cultura, coolhunting, trendwatching, trendspotting.

\section{Trend Studies: an approach for analysing and managing culture}

\begin{abstract}
The present paper intends to discuss the development and consolidation process of Trend Studies, as a transversal area with transdisciplinary characteristics that was developed in connection with the concepts and practices of areas such as Cultural Studies. The numerous perspectives of Trend Studies and their different associations promoted a dispersed development that should be considered and deconstructed by means of finding common points and practices, or different perspectives, to generate a greater cohesion of concepts and methodologies. In this sense, it is important to present a model for the purpose of systematic identification and observation of trends. The result can generate a parallel process of cultural analysis capable of contributing to a basis for the generation of strategic solutions for institutional and social problems, in a new approach to culture management.
\end{abstract}

Keywords: trends, culture, coolhunting, trendwatching, trendspotting. 


\section{INTRODUÇÃO}

Este artigo pretende sistematizar e contextualizar a investigação realizada em meio acadêmico e empresarial no âmbito do estudo de tendências ${ }^{4}$ de cariz cultural e social. Neste sentido, pretende-se gerar um reconhecimento da própria designação de "Estudos de Tendências" ${ }^{5}$, permitindo em simultâneo desmistificar conceitos e associações errôneas que vão surgindo, no que diz respeito às práticas da análise de tendências. Entende-se que esta rápida emergência destes estudos sublinhou carências ao nível da maturidade e da solidez que um campo de inquérito deve possuir, pelo que é natural associar esta abordagem dos Estudos de Tendências a uma área como os Estudos de Cultura - onde iremos concentrar a nossa atenção - por si mesma também transdisciplinar, em próxima articulação com conceitos e práticas da Antropologia, do Marketing (considere-se também a importância da Teoria da Cultura de Consumo), do Design e de outras, já para não falar da importante influência inicial da Teoria da Moda. O contributo dos

\footnotetext{
4 Diferenciamos a prática de estudar tendências - ao abordar o conceito de estudo de tendências - da própria área emergente dos Estudos de Tendências.

5 No seguimento da designação "Estudos de Cultura", este artigo opta por abordar e defender o conceito de "Estudos" de Tendências, entre outros que poderiam ser explorados (como Trendwatching ou Pesquisa de Tendências), sublinhando-se a perspetiva de Fred Inglis: "those fields of study which have, in a conscientiously up to date (...) way, repudiated the monolithic and authoritarian implications of a discipline, and styled themselves, non-referentially, 'studies'. For the designation 'Studies', implying (...) an ecumenical congeries of inquirers, each on friendly borrowing terms with the intellectual methods in the adjacent fields, refuses the old quest for accurate representations of reality and unitary methods of finding them. 'Studies' are provisional, flexible, mobile; the province of equal students rather than teachers (...). They honour the plurality of perspectives, relish the varieties of intellectual experience, acknowledge the location and uncertainty of old knowledge itself" (INGLIS, 1993, p.227).
} 
Estudos de Cultura apoia a contextualização da pertinência do estudo de tendências (como prática), bem como muitas das dinâmicas que estão por detrás dos conceitos usados no meio empresarial. A par da problematização dos conceitos e da contextualização metodológica, este artigo apresenta num segundo momento um mapa/modelo para as práticas de identificação e de análise de tendências, um dos exercícios base dos Estudos de Tendências. Isto sublinha uma relação com abordagens de análise da cultura, numa perspetiva de observação e interpretação, que geram pistas estratégicas que podem ser aplicadas numa ótica de gestão da cultura.

Neste sentido, este trabalho surge como um exercício de investigação fundamental e conceitual, com características ensaísticas, capaz de apoiar consequentes e posteriores pesquisas aplicadas e de trabalho de campo. Esta importante revisão literária mediante a problematização das perspectivas de autores como Raymond Williams (1961/1975), Birgit Neumann e Ansgar Nünning (2012), bem como outros que trabalham esta temática no âmbito empresarial como Henrik Vejlgaard (2008), William Higham (2009), Peter Gloor (2007; 2009), e Martin Raymond (2010) representa um passo necessário para a problematização conceitual e aplicada da área, atribuindo-Ihe uma orientação para o crescimento no meio acadêmico. Não obstante, sublinha-se que o próprio desenvolvimento dos Estudos de Tendências não poderia ter lugar sem o importante papel de instituições acadêmicas como a Fontys Academy for Creative Industries (Países Baixos), a ELISAVA em Barcelona (Espanha), as Universidades Federal e Estadual de Santa Catarina (Brasil) e a Faculdade de Letras da Universidade de Lisboa, que contribuem para a formação e a disseminação de conhecimento nesta área emergente. Isto, a par de redes e consultoras como a Trendwatching, o Future Concept Lab, a Faith Popcorn's Brainreserve, a Science of the Time, o Trends Observer, entre outras, que ajudaram a consolidar a pertinência destes estudos. 
Ao problematizar o contexto do estudo das tendências, estamos a propor uma convergência de conceitos e um mapeamento mais uniforme de práticas que podem gerar melhores abordagens profissionais e de investigação, de forma a apoiar o desenvolvimento de estratégias e soluções mais sustentáveis e inovadoras para os desafios societais e empresariais.

\section{ESTUDOS DE TENDÊNCIAS: CAMINHOS E CONCEITOS}

\subsection{Estudos de Tendências}

As Ciências Sociais fornecem muito do enquadramento conceitual e metodológico enquanto esfera científica para o estudo de tendências. Por sua vez, as Humanidades reforçam uma contextualização das dinâmicas culturais, possibilitando a compreensão do complexo panorama sociocultural. Os Estudos de Tendências apresentam-se assim como uma área transdisciplinar, integrando conceitos, perspectivas e metodologias dos Estudos de Cultura, Antropologia, do Marketing, do Design, entre outros. Os seus objetivos são vários, de acordo com cada abordagem, mas na sua base pretende identificar as mudanças ao nível das mentalidades que, por sua vez, se tornam visíveis no meio social. Desta forma, o seu campo de atuação encontra lugar ao nível dos vários sistemas sociais com dinâmicas próprias - que pretende desconstruir, de forma a apresentar soluções e orientações ao nível estratégico. De forma sintética, os seus objetos de estudo prendem-se com as várias manifestações associadas aos comportamentos sociais, ou seja, procura-se identificar e acompanhar práticas, rituais, representações e discursos - vinculados a determinados artefatos, com o objetivo de compreender comportamentos e mentalidades emergentes que refletem mudanças do espírito de um tempo. A partir de metodologias aplicadas, esta área de estudo analisa também o que está por trás de eventuais mudanças socioculturais e os vários de seus impactos. 
Vale ratificar que embora os Estudos de Tendências facultem visões possíveis do porvir, eles não têm relação com a futurologia. Apesar da já antiga articulação dos Estudos de Tendências com o futuro (DRAGT, 2017; VEJLGAARD, 2008; RAYMOND, 2010), a capacidade de gerar cenários de evoluções de tendências decorre de uma análise diacrônica do desenvolvimento da tendência e das várias mutações que sofreu. A atenção cai aqui sobretudo sobre a necessidade de compreender tendências através da definição de contextos socioculturais sincrônicos e diacrônicos. Isto promove o desenvolvimento de uma contextualização histórica da realidade recente, da mesma forma que revela os potenciais caminhos e eventos futuros. Tal como Sandra Rech sugere, os Estudos de Tendências podem gerar cenários da evolução da sociedade, englobando atividades, atitudes, comportamentos e inquietações sociais ( $R E C H, 2016)$. Todavia, a sua missão não consiste em gerar previsões sobre o futuro, sublinhando apenas a força de alguns padrões e a sua potencial estabilidade num período próximo.

No que tange o caráter transdisciplinar dos Estudos de Tendências, Neumann e Nünning (2012), ao explorarem a ideia de travelling concepts, ponderam que o mundo atual, com as suas formas mobilizadas de vida social - aliadas aos processos de troca global e transdisciplinaridade -, abre o caminho para o aumento da produção de conhecimento que transcenda territórios e disciplinas fixas, reconfigurando e transformando as fronteiras existentes (NEUMANN e NÜNNING, 2012, p.12). Não obstante a transdisciplinaridade dos Estudos de Tendências, da sua perspectiva de análise crítica das dinâmicas culturais e da sua integração em modelos de geração de inovação, importa encontrar um espaço onde eles se possam desenvolver de uma forma sólida e reconhecida. A análise e a gestão da cultura permitem essa associação no âmbito dos Estudos de Cultura. Tal como Raymond Williams (1961/1975) sugeriu, a análise da cultura prende-se com a descoberta da natureza da organização por detrás das relações e uma palavra- 
chave para tal consiste no "padrão", ou seja, a descoberta de padrões e das relações entre eles permite por vezes identificar identidades inesperadas e correspondências em atividades consideradas separadas (WILLIAMS, 1975, p.63). T. S. Eliot, por sua vez, levanta a questão se existiriam padrões permanentes que sirvam de base comparativa entre civilizações e Eras. O autor, no entanto, sugere a dificuldades de se analisar a totalidade dos valores de uma civilização numa época, esteja-se inserido nela ou numa perspectiva comparativa (ELIOT, 1948, p.18), o que consiste um dos desafios dos Estudos de Tendências e da análise cultural associada. A perspectiva social das culturas (WILLIAMS, 1961/1975) e as práticas e representações que as compõem, já para não falar da proximidade com a problemática da análise do espírito do tempo (ARNDT, 1808/2009; CARLYLE，1829/1858; MILL, 1986; HEGEL, 1840/1914; MORIN, 1962/2007; entre outros), assim como o termo structure of feeling (WILLIAMS, 1961/1975), permitem integrar o estudo de tendências nestes âmbitos disciplinares. Isto, em articulação com a própria perspetiva de análise cultural aplicada com vista à melhoria de práticas e de decisões em meio empresarial, social e estratégico, conforme proposto pela nomenclatura profissional do Chief Culture Officer (CCO), de Grant McCracken (2011). Sugerimos, aliás, no âmbito dos Estudos de Cultura, a importância desta associação próxima à Gestão da Cultura, em articulação com a visão deste autor sobre o CCO.

Não obstante, tal como Guillaume Erner sugere, uma sociologia das tendências teria como elementos de estudo as práticas e os objetos que dependem dos gostos coletivos repentinos e convergentes (ERNER, 2016, p.23). Abordando também a importância do conceito de semiologia, o autor evidência a referência no título de um subcapítulo, "la semiologia, ciencia de las tendencias" (ERNER, 2016, p.49). Esta análise das práticas, das representações e dos discursos é abordada nos Estudos de Tendências com vista a uma compreensão profunda dos vários elementos e forças que estão em ação a movimentar e a alterar 
comportamentos e mentalidades. Neste sentido, importa compreender estes fatores de mudança, as shifts e os triggers (MASON et al., 2015, p.52). Sobre os mesmos, Henry Mason e os seus colegas sugerem:

\begin{abstract}
[...] shifts are the long-term, macro changes (such as urban transition, aging populations, and climate change) that play across years or even decades. [...] triggers are more immediate changes that drive the emergence of a trend. These can include specific technologies, political events, economic shocks, environmental incidents, and more (MASON et al., 2015, p.52).
\end{abstract}

A perspectiva dos autores contextualiza os vários tipos de forças em ação. Numa ótica categórica, pode-se acrescentar que as próprias tendências agem como forças de mudança, provocando alterações entre si e nas mentalidades associadas; os eventos disruptivos, muitas vezes "cisnes negros"6 (TALEB, 2007), provocam alterações com efeitos visíveis; e por fim temos condições naturais que podem determinar alterações sociais profundas.

Conclui-se sumariamente que, com base nestes pressupostos, os Estudos de Tendências pretendem analisar um mapeamento das mentalidades baseado num estudo plural da sociedade e das suas dinâmicas. O objetivo consiste em identificar sinais e pistas capazes de gerar novas abordagens e estratégias sólidas e sustentáveis para o tecido social e econômico.

\title{
2.2 Os conceitos e o seu desenvolvimento
}

Para se delimitar as bases dos Estudos de Tendências, faz-se necessário pontuar uma breve problematização de termos como (a) tendência, (b) cool, (c) trendwatching, coolhunting e trendspotting. Para isso, realizou-se uma revisão literária de autores como Malcolm Gladwell (2000), Peter Gloor e Scott Cooper (2007), Henrik Vejlgaard (2008), William

\footnotetext{
${ }^{6} \mathrm{O}$ "cisne negro" é um acontecimento improvável e imprevisível que possui um grande impacto, sobre o qual não temos consciência antes da sua ocorrência (TALEB, 2007).
} 
Higham (2009), Victor Alejandro Gil Mártil (2009), Martin Raymond (2010), Francesco Morace (2013) e Els Dragt (2017). Esta compilação e consequente desconstrução dos conceitos é importante a partir do momento em que nem sempre se verifica consenso entre os autores sobre terminologias e definições. Pode-se considerar, portanto, que os conceitos a seguir se enquadram em certa medida como travelling concepts (NEUMANN e NÜNNING, 2012; BAL, 2002; SAID, 1983). De acordo com Mieke Bal (2002), existem conceitos que transitam entre disciplinas, períodos históricos, áreas geográficas, acadêmicos e até comunidades acadêmicas distintas. Como tal, estes termos - que viajam entre disciplinas - podem possuir significados e valores operacionais distintos (BAL, 2002, p.24). Neumann e Nünning reiteram que o significado dos conceitos não é fixo, mas sim algo que emerge da forma como são repetidamente aplicados, traduzidos e atualizados (NEUMANN e NÜNNING, 2012, p.2-3). Tal como estes autores indicam, esta própria "viagem" dos conceitos promove uma interdisciplinaridade.

Assim, sublinha-se o objetivo deste artigo ao nível da dimensão de uma organização dos conceitos associados a esta área.

(a) Tendência

Torna-se necessário especificar as múltiplas perspectivas sobre a compreensão do termo tendência. Parte-se da multiplicidade de significados atribuídos à palavra que surgem do seu uso intenso em determinados setores, como a moda ou a economia, e também por meio da sua popularização, especialmente por intermédio dos meios de comunicação.

Guillaume Erner (2016) problematiza o conceito de tendências, indicando que o mesmo pode designar os movimentos de fundo da sociedade, bem como fenômenos subterrâneos que podem permanecer invisíveis (ERNER, 2016, p.13), sendo que a expressão já não designa apenas modas, mas também modos de vida (ERNER, 2016, p.17). Todavia, também podemos entender uma tendência como uma nova manifestação na forma de comportamentos, atitudes e expectativas 
de necessidades e desejos humanos fundamentais (MASON et al., 2015, p.46). Os autores sugerem ainda que as tendências são geradas de acordo com as necessidades básicas, motores de mudança e inovações (MASON et al., 2015, p.48) e que diferem das ondas, na medida em que as tendências representam o que fazemos (surgem quando mudanças externas revelam novos modos de responder a necessidades); e a forma como o fazemos, através de produtos e serviços específicos, podem ser ondas (MASON et al., 2015, p.55). De um modo mais específico, Henrik Vejlgaard (2008) expõe três perspectivas para o vocábulo. Em revistas populares, por exemplo, o autor identifica o uso como sinônimo de notícias sobre novos produtos; também aponta que um(a) designer pode se referir às tendências na indústria automóvel, sendo que, neste caso, a tendência significa desenvolvimento de produtos. Por último, ele traz a visão de um sociólogo de tendências, que irá tratar sobre o movimento desta tendência, partindo dos seus promotores (trendsetters) em direção à maioria (mainstream) (VEJLGAARD, 2008, p.08-09); com isso, Vejlgaard (2008), trata a tendência como um processo de mudança. Para o autor, as três concepções citadas estão interconectadas, ao referir que uma tendência é um processo de mudança que, por vezes, ocorre motivado pelo desenvolvimento de um produto e que, ocasionalmente, resultará em outros e novos produtos (VEJLGAARD, 2008, p. 08). Els Dragt apresenta uma definição de tendência, em linha com a proposta de Henrik Vejlgaard, ao sugerir que uma tendência é uma direção de mudança em valores e necessidades que tem lugar através de forças e que se manifesta de várias formas em certos grupos sociais (DRAGT, 2017, p.14). A autora sugere ainda que os elementos-chave para a definição de uma tendência passam por compreender a direção da mudança; os valores e as necessidades associados a essa mudança; as forças que afetam a tendência; as manifestações que podem ser observadas; a identificação dos grupos onde a tendência nasce e se desenvolve (DRAGT, 2017, pp.3637). Sobre esta questão, a autora acrescenta: 
You study change to find patterns that show that people's needs and wants are shifting in certain directions. These patterns of change are called trends. The trends are driven by global forces and already manifest themselves in various ways, like a certain type of style, language, behaviour, a new service or product. These manifestations can be spotted first amongst niche groups in society who are setting the trend or embracing it in an early stage (DRAGT, 2017, p.37).

Vale acrescentar que a própria ideia de tendência, como afirma Victor Alejandro Gil Mártil (2009), abarca as motivações compartilhadas coletivamente que condicionam as escolhas do consumidor e dirigem o seu consumo. Francesco Morace (2013) contextualiza que a complexidade do conceito de tendência é difícil de ser trabalhada em detalhes, porém afirma que "as tendências são aqueles fenômenos em evolução - mais ou menos velozes - ou mais ou menos lentos - que indicam novos elementos no sistema sociocultural" (MORACE, 2013, p.94).

A pluralidade de sentidos também é pontuada por William Higham, sendo que o mesmo destaca que para os cientistas, o termo significa a direção de uma curva; para a indústria da moda, os estilos mais recentes; e para os mais conservadores, significa um termo pejorativo de algo efêmero (HIGHAM, 2009, p.14). O autor apoia a ideia de que os significados coexistem, em níveis científico e social, sendo uma linha de direção ou um movimento geral ao longo do tempo de uma mudança estatisticamente perceptível (HIGHAM, 2009, p.15). Importa perceber a macrovisão citada pelo autor, que explica:

[...] trends are changes that typically occur across thousands and even millions of consumers. They are created by changes in political, economic, socio-cultural or technological environments. They occur because of a complex combination of circumstances. They are not just due to the actions of one individual or commercial concern (HIGHMAN, 2009, p.48). 
Tal como Henry Mason e os seus colegas sugerem, para além das tendências de consumo, existem outras a ter em consideração como as sociais, políticas, econômicas, da indústria, de novas categorias de produtos, macro, de moda e futuristas (MASON et al., 2015, p.83). Sublinhe-se também o caráter crescentemente universal e global das tendências, sendo que os drivers de mudança se manifestam de alguma forma nos vários contextos (MASON et al., 2015, p.147). Urge refletir sobre a proposta dos autores - especificamente William Higham (2009, p.8789), na medida em que, apesar de existirem diferentes tipos de tendências (de acordo com cada sistema social) que se manifestam numa perspetiva mais micro, as macrotendências culturais e sociais afetam de uma forma profunda os vários grupos sociais e os restantes sistemas e tipologias de tendências micro (de consumo; de estilo; político-institucionais; tecnológicas, econômicas, entre outras possíveis). Assim, sugere-se a existência de uma categorização estratificada que vai exercendo influências de acordo com cada categoria, do imaginário coletivo até aos objetos que surgem associados a determinadas tendências. Neste sentido, conforme Morace (2013) sugere, deve-se considerar que, originalmente, as novas tendências "não são explícitas, mas devem ser identificadas, de tempos em tempos, por meio dos chamados "focos" de tendências, ditos, de outro modo, "lugares de efervescência cultural" que se desenvolvem em diferentes países do mundo, abrangendo diferentes alvos, em diversos "teatros" de consumo (a distribuição, as redes sociais e, cada vez mais, também as ruas)" (MORACE, 2013, p.95).

(b) O Cool, as manifestações e os sinais das tendências.

Importa problematizar neste artigo o que são as manifestações das tendências. É recorrente que se confunda 0 conceito de tendência com a sua manifestação. No entanto, constitui-se um equívoco comum, e por isso, merece atenção. Como já explicitado anteriormente, a tendência é considerada 
como uma direção de mudanças e valores, representada por mentalidades, que se manifestará na sociedade de diferentes formas, a partir de objetos, padrões de comportamento, dentre outros. Estes objetos, que vão além do produto físico e podem se apresentar enquanto rituais, estilos e representações, não constituem a tendência em si, mas a sua manifestação. Aliás, tal como Henry Mason e os seus colegas sugerem, as inovações não são tendências, mas sim exemplos, a tendência não existe realmente (MASON et al., 2015, p.54). Cabe ao profissional de tendências analisar essas manifestações, identificar padrões através das mesmas e reconhecer o contexto em que estão inseridas, para posteriormente classificálas e enquadrá-las como elementos de um escopo maior, que apontam para um caminho, ou seja, a tendência em si (este processo de decodificação e análise será explicado no ponto 2 deste artigo). A par de práticas e de rituais, os objetos - artefatos e representações - são entendidos como sinais ou como uma manifestação de tendências. Encontram-se, portanto, no campo do visível. A tendência, por sua vez, enquadra-se no campo do invisível e requer, por esta razão, uma análise profunda para que seja compreendida e identificada.

As tendências podem ser observadas e analisadas através das suas várias manifestações, ou seja, através dos objetos visíveis que podem ser interpretados, funcionando como dados para a análise. Els Dragt sublinha que as manifestações de tendências são sinais de mudança que podem ter aparências diferentes e assumir várias formas, de um objeto artístico a um serviço comercial ou um produto (DRAGT, 2017, p.41). Francesco Morace (2013) pontua ainda que os dados quantitativos serão cada vez mais recolhidos de acordo com leituras específicas da realidade, como forma de dar solidez às várias interpretações que surgem de uma perspectiva mais qualitativa (MORACE, 2013, p.92).

Para abordar o coolhunting, uma das principais ferramentas no âmbito dos Estudos de Tendências, a ser delimitado no ponto seguinte, importa inicialmente 
ponderar o próprio conceito de cool. Um dos acadêmicos que dedicou atenção ao conceito foi Peter Gloor, que nas suas várias obras, em articulação com colegas, problematiza a expressão como algo que vai para além da diversão e que permite tornar o mundo num espaço melhor (GLOOR e COOPER, 2007, p.07), sendo que algo cool deve também sublinhar uma novidade (fresh), permitir a pertença a uma comunidade e atribuir sentido às nossas vidas (GLOOR et al., 2009, p.1-2). Não obstante, sugere-se que o cool advém das massas (BIRD e TAPP, 2008, p.20), ou melhor, ele tem o poder de se massificar ou de providenciar pistas estratégicas para a massificação. Aliás, as inovações podem por vezes gerar um maior valor, pois as ideias mais cool surgem muitas vezes de uma mente coletiva (GLOOR e COOPER, 2007, p.03). Os sinais com as características associadas ao cool possuem um DNA cultural e criativo que podem atribuir pistas estratégicas mais ricas. A par da proposta dos autores já citados, Carl Rohde (2011), através da rede Science of the Time, contribuiu para a compreensão da natureza do cool, sugerindo que o mesmo revela um caráter ou uma atitude atrativos, com uma natureza inspiradora que promove uma ação ou que inspira indivíduos, e com potencial de crescimento (ROHDE, 2011, p.15). Não obstante, deve-se considerar para finalizar que, tal como Malcolm Gladwell sugere, a própria descoberta do cool faz com que ele se mova (GLADWELL, 1997), ou viaje, ou seja, a tomada de consciência global de que algo é cool, faz com que o mesmo seja transferido para outro objeto ou prática.

Com base neste enquadramento conceitual (principalmente nos contributos de ROHDE, 2011; GLOOR e COOPER, 2007; e de GLOOR et al., 2009), este artigo sugere uma definição do objeto cool como a manifestação de uma tendência que se concretiza num sinal criativo, composto num primeiro nível por características atrativas e inspiradoras e com potencial de replicação social; e num segundo nível de análise pelo seu potencial de facilitar a geração de significados, a pertença (a grupos) e a vida em sociedade nas várias atividades quotidianas. 
(c) Os Conceitos de Trendwatching, Coolhunting e Trendspotting.

Como já foi abordado, muitos dos elementos que compõem os Estudos de Tendências foram desenvolvidos ao longo de décadas, em paralelo com o desenvolvimento das disciplinas a que pertencem na sua origem. O coolhunting foi e continua a ser uma das práticas e ferramentas-base desta área emergente. Em 1997, Malcolm Gladwell, no artigo "The Coolhunt", publicado na revista The New Yorker, aborda esta prática e chama a atenção para os profissionais que estavam associados à mesma, na altura ainda muito ligada à moda e ao estilo. Mártil sugere que o trabalho do coolhunter prende-se com a capacidade de identificar indícios de mudança e de interpretar os fatores que favorecem a sua emergência, determinando os impactos que possuem nas tendências e nos negócios das organizações (MÁRTIL, 2009, p.18). Gloor e Cooper (2007) acrescentam a importância do coolhunting como forma de identificar tendências e também os trendsetters (GLOOR e COOPER, 2007, p.7), ou seja, os influenciadores. O coolhunting permite, conforme os autores indicam, observar os mercados externos e libertar a inovação interna (GLOOR e COOPER, 2007, p.9). O problema do coolhunting é que perdeu credibilidade no meio dos Estudos de Tendências e a própria nomenclatura entrou em certo desuso. Tal como Malcolm Gladwell (1997) sugeriu, o coolhunting era mais sobre uma coleção de observações espontâneas que mudavam entre coolhunters e de momento para momento, ao invés da articulação de uma filosofia coerente do cool (GLADWELL, 1997). Atualmente, esta proposta metodológica, ainda em uso por muitos profissionais, é insuficiente e coloca em causa a própria idoneidade da prática. Neste sentido, importa contextualizar a prática do coolhunting num conjunto de metodologias que confirmam os resultados entre si e que ajudam a enquadrar os sinais identificados e as pistas que eles revelam, sendo que seria inclusive pertinente articular esta prática com as perspectivas presentes na visita dadaísta, na deambulação surrealista e na deriva 
situacionista7. Para tal, deve-se indicar a integração de uma dupla perspectiva de observação que tenha em atenção a fast culture e a slow culture (MCCRACKEN, 2011), de modo a identificar os sinais de criatividade emergentes, bem como o seu contexto numa tradição e em narrativas já com grande densidade cultural.

Do conceito de coolhunting passamos para o trendspotting e o trendwatching. Muitas vezes abordados como iguais, deve-se entender cada um no âmbito literal da própria nomenclatura. Assim sendo, a prática de trendspotting prende-se com o processo de identificação de tendências enquanto o trendwatching pressupõe o acompanhamento do desenvolvimento e mutação das tendências, ou seja, das suas alterações e

\footnotetext{
7 A prática de descoberta dos sinais criativos e do cool no espaço físico pode ganhar insumo com as abordagens e perspectivas destas formas de explorar a cidade. Para o efeito, recorremos à obra de Francesco Careri para desconstruir estas perspectivas de percurso como ato de travessia, a linha que atravessa o espaço e o relato (2002/2013, p.31). No âmbito da visita dadaísta - como uma excursão aos lugares banais da cidade (CARERI, 2002/2013, p.71) - propõe-se um habitar da cidade do banal (CARERI, 2002/2013, p.74), descobrindo continuamente relações inesperadas (CARERI, 2013, p.239). Conforme o autor, o espaço escolhido para visita revela-se um espaço simultaneamente familiar e desconhecido, visível, mas não frequentado, banal e inútil. Com esta prática, a visita dadaísta cria as bases para a pesquisa do inconsciente da cidade, a ser desenvolvida pelos surrealistas (CARERI, 2002/2013, p.77). Os surrealistas compreenderam que exista algo mais nesses espaços e definiram esse vazio como um inconsciente urbano - uma cidade dotada de um inconsciente próprio (CARERI, 2013, p.239). Se a visita Dada sublinhava o banal e o ridículo, os surrealistas ponderaram a possibilidade da descoberta de um novo mundo para além da negação, a cidade pode conter uma realidade não visível (CARERI, 2002/2013, p.82-83). Por sua vez, conforme o autor defende, os situacionistas adicionam a psicogeografia como instrumento de análise, e procuravam, por meio da dérive (deriva), os lugares fora da cultura dominante e dos itinerários turísticos (CARERI, 2013, p.240). Estas perspectivas e abordagens poderiam contribuir para a prática do coolhunting, na medida em que: 1) uma visitacom um viés inspirado na ação dadaísta ao espaço banal permite contextualizar a investigação e a recolha de sinais do coolhunt, opondo de alguma forma o que é cool ao que não é, ou seja, ao compreender os espaços que não promovem objetos e narrativas cool torna-se possível contextualizar melhor os que possuem essas características cool; 2) A deambulação pode levar o coolhunter a encontrar o que "ainda não foi descoberto" e a procurar os sentidos escondidos por detrás dos espaços e dos objetos; 3) A questão do registro psicogeográfico do tecido urbano pode ajudar na categorização dos próprios sinais identificados em cada espaço. Assim, o coolhunting tem o potencial de encerrar em si uma abordagem de observação e registo de sinais criativos e cool, numa articulação de práticas de inspiração etnográfica e de um "caminhar como prática estética" (expressão abordada por Careri, 2002/2013) como formas de contextualizar a informação recolhida.
} 
do seu impacto na sociedade. No meio empresarial, ambos os conceitos dizem respeito ao processo de identificação e de análise de tendências, por norma no âmbito da cultura de consumo. Porém, também existe o próprio conceito de pesquisa de tendências (trends research), abordado, por exemplo, por especialistas dos Países Baixos (vd. DRAGT, 2017). O fato de não existir um consenso ao nível dos conceitos e das práticas entre os vários profissionais e autores é um aspecto que merece atenção, daí a importância da crescente convergência para a uniformização. Não obstante, ainda existem diferenças entre as várias abordagens, mesmo dentro de correntes semelhantes, como a Portuguesa e a dos Países Baixos. Els Dragt afirma que:

The domain of trend research is fairly new and some wonder if it is a legitimate profession at all. While many other professions have manifestos, codes of conduct and ethical guidelines, anyone can call themselves a trend researcher. There is not a specific stamp of approval needed from a trend inspector. The field is still very much under construction and in the midst of building a shared body of knowledge (DRAGT, 2017, p.23).

Estas várias ferramentas dos Estudos de Tendências baseiam-se principalmente na análise qualitativa. Tal como Els Dragt sugere, pretende-se recolher informação de uma forma sistemática sobre situações, eventos e indivíduos, de forma a obter um conhecimento profundo sobre o comportamento humano através de processos de observação e de inquérito (DRAGT, 2017, p.55). A autora acrescenta que:

A trend researcher should be: Curious: you are eager to absorb knowledge and experiences, you have an inquisitive nature and always wonder about the 'why' of things happening around you [...]; Non-judgmental: you have an open minded personality and are able to show empathy [...]; Interdisciplinary: you have a varied skill set involving many areas of knowledge [...]; Holistic: you look at the bigger picture and how this fits with the details [...]; Analytic: you use a structured approach to examine signs of change and operate in a careful, critical and objective way to identify 
causes and key factors behind shifts; [...] Creative: you are able to see connections between shreds and snippets of information that seem unrelated at first [...]; Persistent: you are not satisfied easily and want to research beyond the baseline and dive deep into matters [...]; Visual: you have a flair for visual language and are able to use visual aids to bring your research findings to life [...]; Recognisable: you do research in a way that sets you apart from others and leave a personal fingerprint on your reports and presentations [...]; Storyteller: you are able to get your trend story across and adapt it to different audiences without losing your personal touch (DRAGT, 2017, p.25-26).

Os desenvolvimentos científicos portugueses ao nível da base dos Estudos de Tendências partem dos conceitos holandeses desenvolvidos, entre outros, por especialistas como Carl Rohde (2011). Porém, ainda existem diferenças e uma das principais baseia-se na própria relação com a questão do futuro. Els Dragt sugere que a investigação de tendências prende-se com a detecção de sinais de mudanças que estão a ocorrer neste momento e como eles indicam direções com futuros possíveis (DRAGT, 2017, p.19). Ao indicar a genealogia dos Estudos do Futuro, a autora sugere uma articulação próxima dos mesmos com os Estudos de Tendências (DRAGT, 2017, p.16). A perspectiva portuguesa assume que o estudo diacrônico de uma tendência - da sua densidade cultural e estabilidade, ou resistência a mudanças - permite identificar cenários de curto prazo sobre o desenvolvimento da mesma, mas reconhece que a possibilidade de "cisnes negros", bem como a complexa rede de atores e de influências, torna demasiado complexa a previsão de cenários futuros.

\section{MODELO DE TRENDWATCHING E TRENDSPOTTING}

\subsection{Fase 1- observação cultural e recolha de dados}

O processo de análise de tendências implica a observação dos comportamentos humanos no seu ambiente natural, distinguindo as diversas 
manifestações e objetos resultantes das tendências. Assim, o entendimento do peso das características visíveis e invisíveis das tendências é possibilitado pela apreensão dos elementos socioculturais envolvidos. Para tal fim, o analista de tendências aborda métodos quantitativos e qualitativos para averiguar e reconhecer as tendências de fundo, micro e macro, que norteiam o espírito do tempo. Henrik Vejlgaard providencia um conjunto de indicações a ter em consideração no início do processo de trendspotting: 1) As tendências são criadas por pessoas e deve-se observar as que criam, ou estão preocupadas, com estilos novos e inovadores; 2) Trendspotting é possível através da observação, seja no mundo real, ou a partir dos media; 3) Geralmente, as tendências são "cozinhadas" antes de entrarem em "ebulição"; 4) Se um estilo novo e inovador pode ser detectado em duas ou mais indústrias simultaneamente, é provável que se trate de uma tendência; 5) Uma nova tendência costuma ser uma reação ao que se tornou "mainstream" ou ao que está no mercado há vários anos; 6) Mudanças de estilo geralmente vão de um espectro a outro; 7) O trendspotter deve ter em consideração os mínimos sinais de mudança e depois analisá-los (VEJLGAARD, 2008, p.27).

O início de um processo de análise e mapeamento de tendências começa então com a observação e recolha de dados, para depois passar à sistematização e análise dos mesmos. Els Dragt sugere três fases para a pesquisa de tendências: observar; analisar; aplicar (DRAGT, 2017, p.54). A primeira fase articula-se com a observação cultural aqui em estudo, sublinhando a importância da seleção dos sinais, bem como a sua documentação. A autora explora o conceito da observação e as suas implicações:

SCAN: the art of looking sideways [...] Scanning the world means having your radar on always, anytime, anywhere. [...] Trend researchers scan the environment using various sources which can mainly be divided into two categories: Field research sources like street hunting, innovator interviews and attending events; Desk research sources like 
reading magazines, monitoring online media and watching documentaries (DRAGT, 2017, p.54).

Desde já, a autora indica elementos relevantes para esta fase, tais como o trabalho de campo, o contato com indivíduos e a presença em determinados eventos ou atividades, bem como a recolha de informação em meios digitais e publicações periódicas. Estes meios são fontes importantes para recolher informação e desenhar o largo contexto que permite compreender e identificar mudanças no tecido sociocultural. Henry Mason e os seus colegas (2015) vão ao encontro da visão da autora, sugerindo:

How to identify consumer trends: 1) Look for "clusters" of multiple innovations that indicate a number of actors putting similar bets on the future and that are creating new levels of customer expectation. 2) Don't limit your search to product innovation. We look for four types (vision, business model, product/service/experience, marketing). 3) The more diverse the range of innovations you spot, the more reliable your insights about future customer needs and wants. Look for innovation that show how the trend is playing out in different contexts (MASON et al., 2015, p.70).

Os autores ainda sublinham a importância de ter em consideração fontes como os media tradicionais, publicações de negócios, newsfeed de empresas, as redes sociais, conferências e eventos, uma rede de spotters (MASON et al., 2015, p.79-81), entre outros. William Higham também deixa pistas importantes sobre este processo ao indicar que a observação primária pode ter lugar informalmente no campo ao observar e interrogar consumidores, o que pode envolver imersão, práticas etnográficas, entrevistas, fotografia e outros, sendo que as técnicas de observação formais trazem consigo rigor e uma sistematização do processo (HIGHAM, 2009, p.50). A proposta destes autores, no âmbito desta questão da observação e da recolha de dados, também se encontra em sintonia com a perspectiva de Martin Raymond (2010) sobre a 
triangulação cultural. Esta última é uma abordagem importante a ter em conta nestes processos. Tal como o autor sugere, a triangulação é um conceito que surge das ciências sociais como um cruzamento de dois métodos entre três possíveis para se chegar a uma conclusão similar e confirmar a validade da mesma, sendo também uma forma de traçar ou de validar mudanças a ter lugar na cultura, mediante o uso de métodos que se validam entre si (RAYMOND, 2010, p.122). Martin Raymond (2010, p.205) sugere ainda que o termo triangulação cultural foi inicialmente cunhado por Christopher Sanderson, em 2001, para descrever um método para identificar tendências, que teria sido desenvolvido posteriormente pelo Future Laboratory. Porém, o conceito tem sido explorado no âmbito do estudo da cultura, pois segundo Paula Saukko:

[...] if one wants to combine approaches, one needs a framework that helps to do this. Traditional social and cultural inquiry usually refers to techniques of combining different theories, methods, sources and materials in terms of 'triangulation' (Denzin 1989; Flick, 1998). The classical aim of triangulation is to combine different kinds of material or methods to see whether they corroborate one another. [...] All in all, the classical aim of triangulation is to get a more accurate or truthful picture of the social world. This aim reflects the original meaning of triangulation, which comes from navigation, where it refers to the use of different bearings to give the correct position of an object (Silverman, 1992: 156) (SAUKKO, 2003, p.23).

Não obstante, a abordagem de Martin Raymond (2010) explora um conjunto de práticas para recolher e analisar dados quantitativos e qualitativos, conforme o mesmo resume:

Cultural triangulation is a combination of three distinct but mutually beneficial processes [...]. They are: interrogation: the use of quantitative survey techniques, including household surveys and expert interviews, to poll individuals or groups about their attitudes or activities, with a view to determining the percentage breakdown 
of these attitudes or activities in relation to the larger population or cultural mainstream; observation: the use of a set of qualitative tools such as ethnography and visual profiling to shadow and observe individuals or consumers involved in a particular task or lifestyle activity, with a view to learning more about that task or activity; intuition: drawing on your experiences as a forecaster to add a further layer of insight to the qualitative and quantitative underpinnings acquired during the interrogation and observation stages (RAYMOND, 2010, p.120).

Para o nosso estudo, teremos neste momento em maior consideração as duas primeiras fases, compreendendo que a intuição deve pautar todo o processo, esperando-se do analista que utilize a sua experiência para orientar o trabalho e a análise. Ainda de acordo com Martin Raymond, após as fases de interrogação e de observação, ter-se-á completado a desk research que traz dados que ajudam a contextualizar a questão ou o cerne da investigação inicial e que se articulam com as entrevistas de painéis (capazes de adicionar novas pistas e direções); a pesquisa quantitativa que adiciona contexto e que ajuda a identificar as formas como uma tendência potencial pode estar a impactar o consumidor; e a identificação de características-chave das tipologias de consumidor, que são vitais para compreender uma tendência (RAYMOND, 2010, p.136). Em pormenor, ao nível da fase de interrogação (RAYMOND, 2010, p.122), sublinhamos as práticas de information amnesty, o subject framing, $\mathrm{e}$ as pesquisas quantitativas. A primeira diz respeito ao início da triangulação cultural e pretende compreender o cliente e obter todas as informações relevantes para a questão em mãos (RAYMOND, 2010, p.123). A segunda pretende identificar todos os fatores externos que podem ter impacto na questão, sendo que aqui, o foco está nas tendências, e nas informações mais recentes que podem estar a afetar o mercado ou o grupo de consumidores em foco. Isto é possível ao usar informação de outras redes de tendências e organizações, para depois, após a identificação das tendências e pistas, desenhar um quadro que 
identifique as tendências em fase inicial relacionadas com a questão e as áreas que necessitam de mais investigação, bem como os nomes de especialistas que aparecem recorrentemente na literatura (RAYMOND, 2010, p.124). Sobre a terceira (RAYMOND, 2010, p.129), podemos resumir que se pretende recolher dados relevantes sobre os grupos de indivíduos relacionados com as tendências em estudo.

No que diz respeito à fase de observação (RAYMOND, 2010, p.135), importa sublinhar um mapeamento etnográfico. Esta fase sugere a relação entre os Estudos de Tendências e as práticas de inspiração etnográfica. Sobre esta questão, o autor sugere:

You can carry out ethnographic studies in a number of ways: by identifying a typology you are keen to shadow or track; by asking your target group to keep diaries or activity logs that capture a sense of their day in relation to the area or subject under review; by asking your target group to record, photograph or digitally capture key highlights of the activities you which to observe; by uploading diaries, visuals, texts, footage, etc, to a designated social networking site you have been granted access to (RAYMOND, 2010, p.136).

Martin Raymond acrescenta ainda que se pretende compreender melhor quem são os públicos em estudo, o que fazem, como fazem e o que isso significa para a tendência ou questão em análise, sugerindo que as imagens e os diários devam ser estudados e analisados, de modo a obter pistas que podem sugerir formas de como as tendências influenciam o grande público (RAYMOND, 2010, p.136). Porém, ao analisar as perspectivas do autor, não fica clara uma distinção metodológica para a identificação de uma tendência, para o desenvolvimento de um projeto aplicado ou para a resolução de uma questão. Na realidade, em certos momentos, o objetivo principal do exercício não parece sublinhar a observação, identificação e análise de tendências emergentes. Neste sentido, para efeitos deste artigo, importa indicar a existência de uma distinção entre a prática de aplicação 
do estudo de tendências em projetos ou orientações estratégicas, e o processo específico de identificação e análise de tendências, sendo este segundo o objeto do nosso trabalho.

Sobre a prática de coolhunting, considera-se que esta desempenha um papel importante nesta primeira fase de recolha de informação. O coolhunt é a atividade de investigação no terreno e de trabalho de campo - online e offline - onde se observa o meio social, identificando sinais cool e registrando os mesmos para análise posterior. Com base no método de registro dos sinais cool desenvolvido por Carl Rohde para a rede Science of the Time (ver também ROHDE, 2011), propomos que se tenha em consideração o seguinte modo de registro dos sinais criativos, capaz de gerar uma categorização mais detalhada dos elementos:

a. Ao registrar o sinal, deve-se indicar elementos visuais da observação. William Higham aponta o benefício de ter um registro de uma imagem estática ou mesmo vídeo (HIGHAM, 2009, p.202). Caso seja uma recolha digital - vídeo ou imagem - é necessário citar sempre a fonte. No caso de um registro próprio, deve-se colocar o local e a data do registo, bem como a autoria. $O$ elemento visual ajuda o leitor e o analista a melhor contextualizarem o sinal.

b. Urge dar um título sugestivo que indique o melhor possível o teor do sinal.

c. Deve ser indicada a descrição do sinal, incluindo o seu contexto sociocultural e os indivíduos ou grupos a que diz respeito. Se possível, devem ser associadas ligações da internet para mais informações.

d. Após a descrição do sinal, deve-se indicar a natureza cool por detrás do mesmo, justificando, como já vimos, a razão pela qual é atrativo, vanguardista, inspirador e com potencial de replicação.

e. Este último elemento leva à exploração do(s) insight(s), ou seja, as pistas criativas do sinal que ajudam a compreender a tendência ou que podem vir a ser úteis na geração de inovação e na delineação de estratégias. 
f. Por fim, importa sempre indicar a relação do sinal com tendências já identificadas, mesmo que ele possa ser indicador de mutações sociais.

O coolhunting, como prática associada desde o início à identificação e análise de tendências, desempenha nesta fase um papel de claro destaque. Os seus resultados permitem ilustrar os restantes dados recolhidos, tirando proveito destes últimos para melhor contextualizar os seus próprios sinais registados.

Em tom de resumo e de sistematização, tendo revisto os vários autores e modelos, e considerando o papel importante do coolhunting (DRAGT, 2017; MORACE, 2013; ROHDE, 2011; GLOOR e COOPER, 2007; GLADWELL, 1997; entre outros) e da triangulação cultural (RAYMOND, 2010) numa proposta metodológica para esta etapa, nesta primeira fase de observação cultural e de recolha de dados, propomos um modelo de práticas que incluam:

a. Um enquadramento da tendência ou da questão em estudo, cruzando dados de várias fontes, incluindo redes de tendências e opiniões de especialistas;

b. Uma pesquisa qualitativa junto dos consumidores e stakeholders que inclua entrevistas; inquéritos e questionários sobre as tendências ou a questão em estudo;

c. Uma desk research que resulte num conjunto de dados e estatísticas que ajudem a contextualizar a informação. Uma prática de clipping pode ser útil como ferramenta para reunir dados importantes numa análise posterior;

d. O desenvolvimento de um ou mais coolhunts para delinear elementos emergentes e o seu contexto diacrónico num espaço sociocultural em mutação;

e. Um mapeamento de inspiração etnográfica que permita compreender os vários elementos chave dos grupos de consumidores. 


\subsection{Fase 2 - sistematização da informação}

Por vezes desconsideradas, as práticas associadas à sistematização da informação revestem-se de um papel fundamental para a articulação dos vários dados recolhidos durante a fase anterior. Aqui, os vários elementos recolhidos são analisados de forma sistemática e agrupados de acordo com a afinidade temática, as informações e as pistas que a análise permite obter. O cruzamento de dados que indicam ou espelham fenômenos semelhantes permite criar agrupamentos de informações que se confirmam entre si e que sugerem respostas comuns sobre 0 desenvolvimento das tendências e as mudanças no tecido sociocultural. Aliás, neste exercício de associações começa-se a ter uma melhor perspectiva sobre as dinâmicas a ter lugar:

Once you have been scanning the business arena for some time, you should find that the vast majority of new innovations you see fit into the existing trends in your trend framework [...] when a new innovation that's exciting customers doesn't fit satisfactorily into any of your existing trends; when multiple examples of a trend start to point toward a new and specific direction. These are all signs that you may be witnessing the emergence of a new trend, or the evolution of an existing trend (MASON et al., 2015, p.112).

Assim, cada grupo de dados e informações representa a base para a construção do DNA de uma tendência ou para a verificação de mudanças na natureza de uma tendência já identificada. Novamente, a experiência, o conhecimento e a intuição do analista desempenham um papel importante neste exercício, na medida em que é necessário cruzar elementos que, à primeira vista, poderiam parecer não ter correlação.

Em tom de resumo e de sistematização, após a recolha e o registro de dados na primeira fase, nesta segunda fase de sistematização dos dados, propomos um modelo de práticas que incluam:

a. Agrupamento dos vários dados de acordo com as afinidades e pistas que sugerem sobre mudanças no tecido sociocultural. 
b. Análise de cada grupo de dados, de modo a retirar as conclusões sobre o contexto das mudanças socioculturais e novos movimentos que estão a surgir.

c. Apresentar de forma sistemática as várias conclusões sobre cada grupo de dados, de modo a que possam ser aplicadas na fase seguinte.

\subsection{Fase 3 - desenho e arquitetura do DNA da tendência}

Esta é a fase final do modelo onde, com base nas conclusões da sistematização dos dados, tem lugar a identificação de uma nova tendência ou de alterações na natureza e impacto de uma tendência já identificada. A proposta de análise de Els Dragt (2017) articula-se com a fase de desenho e de arquitetura do DNA da tendência, no entanto, nela também se encerram as práticas de sistematização da informação presentes na segunda fase já descrita (sistematização da informação). Sobre a fase de sistematização/análise, incluindo a validação e a atribuição de uma nomenclatura, a autora defende:

ANALYSE: connecting the dots [...] One manifestation of change is not yet a trend. While scanning you collect a lot of information and making sense of your findings is the next phase of the trend research process. In this phase you will move from trend spots to underlying shifts in values and needs. You will uncover patterns between manifestations and turn these into meaningful clusters of trends and describe and visualise these in an inspiring way for others to understand too (DRAGT, 2017, p.54).

Tal como Els Dragt sugere, a articulação da análise de vários sinais permite descobrir padrões o que leva à terceira fase aqui proposta, a de apresentação da natureza de uma tendência. Isto representa a atribuição e formas de representação de uma titulação da tendência e da sua narrativa (vd. DRAGT, 2017, p.122-127). Quando a sistematização da informação permite identificar novos padrões comportamentais, ou alterações nos já existentes, o analista de tendências 
deve interpretar estas alterações e desenhar o DNA da tendência, construindo um texto capaz de refletir com exatidão a natureza da mesma, os seus impactos e potenciais, bem como o seu enquadramento no contexto cultural do momento. O título e o texto da tendência devem ser claros e objetivos, bem como capazes de serem compreendidos por públicos diferenciados, ou seja, por um público especializado, assim como pelo grande público.

Neste sentido, resumindo a terceira e última fase do modelo, propõe-se o seguinte conjunto de práticas:

a. Com base no grupo de dados sistematizados, $\mathrm{o}(\mathrm{s})$ analista(s) deve $(\mathrm{m})$ proceder à construção do DNA da tendência, tendo em conta a natureza da mesma e o seu potencial para guiar estratégias e a geração de inovação, atribuindo uma nomenclatura à mesma.

b. A descrição da tendência deve conter um texto resumido capaz de ilustrar claramente a natureza da tendência, podendo ter associado um texto descritivo de maior dimensão, capaz de explorar em maior profundidade o contexto, os públicos, os setores, os impactos e as diferenças culturais onde a tendência se manifesta.

c. Os novos textos descritivos de tendências, seja de uma nova tendência ou da alteração da natureza de uma tendência já identificada, devem passar por um processo de discussão entre especialistas, onde o texto descritivo e os dados em que 0 mesmo se baseia são discutidos numa perspectiva crítica, de forma a validar os mesmos. A aprovação por pares é importante para validar o estudo, sendo que se propõe, sempre que for apropriado, a aplicação do modelo Delphi, ou semelhante.

d. Após o período de discussão sugerido no ponto anterior, o analista responsável pelo texto da tendência deve rever a descrição e agir em conformidade com as conclusões da discussão sobre a mesma. Este é o último passo onde se apresenta o título e o texto descritivo da tendência, bem como os dados que fundamentam o estudo. 
Importa sublinhar que este exercício de identificação de tendências, apesar de possuir características e um potencial prospectivos, não pretende prever o futuro. Contudo, tal como Els Dragt (2017) sugere, permite usar as pistas que surgem da análise de tendências para explorar cenários possíveis de futuro e o próprio desenvolvimento e impacto de uma tendência, providenciando um quadro para a exploração sistemática de mudanças (DRAGT, 2017, p.23). Ao articular o estudo da evolução passada de uma tendência com a sua natureza atual, é possível constatar o nível de estabilidade de uma tendência, ou seja, se tem sofrido muitas mudanças ao nível do seu DNA e o impacto na sociedade. Este estudo histórico permite antever a curto prazo 0 potencial desenvolvimento da tendência e como pode ser abordada ao nível estratégico. Este exercício específico diz respeito à Arqueologia de Tendências e à sua articulação com a aplicação estratégica da análise de tendências.

Neste sentido, esta proposta metodológica que de certa forma se articula com uma observação e análise da cultura - vai igualmente ao encontro de uma gestão da cultura ${ }^{8}$, na medida em que os dados analisados promovem pistas estratégicas para a geração de soluções para problemas ao nível empresarial, social, institucional e inclusive político. Ao compreender as sementes da mudança sociocultural, os seus contextos e as dinâmicas sociais associadas, torna-se possível tomar decisões de forma mais informada e, inclusive, gerar inovação e potencializar processos criativos. Estes elementos podem ser trabalhados num segundo conjunto de modelos que aplicam e tomam partido da informação gerada ao nível do Trendspotting e Trendwatching.

\footnotetext{
${ }^{8}$ Aqui a "gestão da cultura" não é entendida na sua concepção mais tradicional de aplicação de conceitos e práticas da gestão ao nível das artes e do sector cultural, mas sim ao nível da aplicação de uma análise cultural no âmbito estratégico e das práticas empresariais (vd. MCCRACKEN, 2011), podendo ser também pertinente em novas abordagens como o Branding Cultural (vd. HOLT, 2004).
} 


\section{DISCUSSÃO E CONSIDERAÇÕES FINAIS}

A concentração atual do estudo de tendências (a prática de análise de tendências por oposição à área transdisciplinar acadêmica dos Estudos de Tendências) no meio empresarial e a sua deslocação para o meio acadêmico colocam entraves que a presente revisão literária sugere, na medida em que muitos dos importantes autores da área não são investigadores inseridos na academia, mas sim profissionais de redes e de consultoras. Neste sentido, sublinha-se a pertinência da investigação científica neste meio e a contextualização de algumas das principais obras temáticas da área (DRAGT, 2017; MASON et. al., 2015; RAYMOND, 2010; HIGHAM, 2009; VEJLGAARD, 2008; GLORR e COOPER, 2007), de modo a identificar o estado da arte sobre a matéria. Apesar das muitas divergências de abordagens e de perspectivas sobre os conceitos, a maioria destes autores articula um conjunto de elementos de definição comuns, o que permitiu a discussão e a configuração aqui apresentada sobre conceitos como tendência e cool. Um dos elementos que devem ser considerados é a ideia de "mudança" e a sua importância na definição e no entendimento de tendência (DRAGT, 2017; MASON et al., 2015; HIGHAM, 2009; MÁRTIL, 2009; VEJLGAARD, 2008), bem como na forma de identificar e analisar este fenômeno. A própria complexidade da análise requer esta perspectiva transdisciplinar que se sugeriu, na medida em que exige que o analista de tendências tenha uma formação sólida e transversal que integre diferentes conhecimentos científicos e práticas para a observação e compreensão do impacto do espírito do tempo no quotidiano dos indivíduos e dos seus grupos.

A revisão literária desenvolvida e a consequente problematização dos conceitos e dos métodos sugere um mapa de investigação e de trabalho de campo contextualizado no âmbito dos Estudos de Cultura, especificamente ao nível da Gestão da Cultura, sem deixar de lado uma ligação transdisciplinar com áreas como o Marketing e o 
Design. Não obstante, importa ainda desenvolver e explorar estas associações, apresentando soluções e articulações aplicadas com estas outras disciplinas, de modo a criar um prisma teórico ainda mais transversal que permita uma viagem entre conceitos e metodologias. Cabe agora em estudos futuros, associar perspectivas e ferramentas que criem modelos para a gestão de projetos com múltiplas variantes e espaços de intervenção. O modelo aqui apresentado para o processo de Trendspotting e de Trendwatching articula um conjunto de conceitos e de práticas reconhecidos na área e apresenta um caminho concreto e sistemático para a identificação e a análise de tendências, pelo que importa desenvolver esforços para a problematização de modelos aplicados que integrem os resultados da análise de tendências na geração de estratégias e de inovação.

\section{Referências}

ARNDT, Ernst Moritz. Arndt's Spirit Of The Times: being the work for the publication of which the unfortunate palm, of erlangen, was sacrificed by napoleon, the destroyer. Tradução de Peter Will. Kila: Kessinger Publishing Co, 2009 [1808].

BAL, Mieke. Travelling Concepts in the Humanities: a rough guide. Toronto: U. of Toronto Press, 2002.

BIRD, Sarah; TAPP, Alan. Social Marketing and the

Meaning of Cool. apud Social Marketing Quarterly. Vol 14, Issue 1, pp. 18 - 29, 2008.

CARERI, Francesco. "Transurbância + Walkscapes Ten Years Later". apud Redobra. Tradução de Federico Bonaldo, No 11, pp.235-247, 2013.

CARERI, Francesco. Walkscapes, O Caminhar Como Prática Estética, São Paulo: Editora Gustavo Gili, 2013 [2002].

CARLYLE, Thomas. Signs of the times. In The Collected Works of Thomas Carlyle. London: Chapman and Hall, 1858 [1829].

DRAGT, Els. How To Research Trends - Move Beyond Trend Watching To Kickstart Innovation. Amsterdam: BIS Publishers, 2017. 
ELIOT, Thomas Stearns. Notes Towards the Definition of Culture. London: Faber and Faber Limited, 1948.

ERNER, Guillaume. Sociología de las Tendencias.

Tradução de Cristina Zelich. Barcelona: Gustavo Gili, 2016.

GLADWELL, Malcolm. "The coolhunt: who decides what's cool? Certain kids in certain places-and only the coolhunters know who they are". apud The New Yorker, 1997. Disponível em: http://www.newyorker.com/magazine/1997/03/17/thecoolhunt (acesso em 02/08/2017)

The Tipping Point - How Little Things Can Make a Big Difference. Boston/New York: Little, Brown and Company, 2000.

GLOOR, Peter; COOPER, Scott. Coolhunting: chasing down the next big thing. New York: Amacon, 2007.

; KRAUSS, Jonas S.; NANN, Stefan. "Coolfarming -

How Cool People Create Cool Trends". Boston: MIT Center for Collective Intelligence \& Galaxyadvisors, 2009.

HEGEL, Georg. Lectures on the Philosophy of History. Tradução de J. Sibree. London: G. Bell and Sons, 1914 [1840].

HIGHAM, William. The Next Big Thing - spotting and forecasting consumer trends for profit. London: Kogan Page, 2009.

HOLT, Douglas. How Brands Become Icons: the principles of cultural branding. Boston: Harvard Business School Press, 2004.

INGLIS, Fred. Cultural Studies. Cambridge: Blackwell, 1993.

MÁRTIL, Victor. Coolhunting - el arte y la ciencia de descifrar tendencias. Barcelona: Empresa Activa, 2009.

MASON, Henry; MATTIN, David; LUTHY, Maxwell;

DUMITRESCU, Delia. Trend Driven Innovation. New Jersey: Wiley, 2015.

MCCRACKEN, Grant. Chief Culture Officer - How to create a living, breathing corporation. New York: Basic Books, 2011.

MILL, John Stuart. The Spirit of the Age. apud: The Collected Works of John Stuart Mill, Volume XXII Newspaper Writings December 1822 - July 1831 Part I, ed. Ann P.Robson and John M. Robson. Toronto: University of Toronto Press, London: Routledge and Kegan Paul, 1986.

MORACE, Francesco. O que é o Futuro? Tradução de Kathia Castilho. São Paulo: Estação das Letras e Cores, 2013.

MORIN, Edgar. A Cultura de Massas no Século XX: 0 espírito do tempo. 9 ed. Tradução de Maura Ribeiro Sardinha. Rio de Janeiro: Forense Universitária, 2007 [1962].

NEUMANN, Birgit; NÜNNING, Ansgar (Eds.). Travelling Concepts as a Model for the Study of Culture.

Berlin/Boston: De Gruyter, 2012. 
RAYMOND, Martin. The Trend Forecaster's Handbook. London: Lawrence King, 2010.

RECH, Sandra. Tendências: a efígie da sociedade materializada no estilo e consumo. Entrevista a Leslie Chaves. apud IHU on-line, Edição 486, 2016. Disponível em: http://www.ihuonline.unisinos.br/artigo/6465-sandra-reginarech (acesso em 25/01/2017).

ROHDE, Carl. Serious Trendwatching. Tilburg: Fontys University of Applied Sciences and Science of the Time, 2011.

SAID, Edward. Travelling Theory. The world, the text, and the critic. Cambridge, MA: Harvard UP, 1983.

SAUKKO, Paula. Doing Research in Cultural Studies: an introduction to classical and new methodological approaches. London: Sage, 2003.

TALEB, Nassim N. The Black Swan: the impact of the highly improbable. New York: Random House, 2007.

VEJLGAARD, Henrik. Anatomy of a Trend. New York: McGraw-Hill, 2008.

WILLIAMS, Raymond. The Long Revolution. Harmondsworth: Penguin Books, 1975 [1961]. 